\title{
Letter to editor on "Efficiency of bimaxillary advancement surgery in increasing the volume of the upper airways: a systematic review of observational studies and meta-analysis"
}

\author{
S. S. Rana ${ }^{1} \cdot$ Om Prakash Kharbanda ${ }^{1}$
}

Received: 15 May 2016/Accepted: 25 May 2016/Published online: 3 June 2016

(C) Springer-Verlag Berlin Heidelberg 2016

We read with great interest, the recent article published by Rosario HD describing the efficiency of bimaxillary advancement surgery in increasing the volume of the upper airways: a systematic review of observational studies and meta-analysis [1]. We congratulate the authors for conducting a systematic review and meta-analysis of such a meaningful and much warranted topic using cone beam computed tomography. In this study, authors located 1860 relevant studies on the subject. They found only six studies suitable according to PRISMA guidelines for quantitative meta-analysis. It is pertinent to mention here that upper airway and its definition include both pharynx and the nasal cavity [2]. The short listed and included studies in this review provided data on pharyngeal volume only, and none of the studies included nasal cavity volume, an integral part of upper airway. It is well known that high nasal resistance is one of the major contributing factors of obstructive sleep apnoea (OSA), and it comprises nearly two-thirds of the airway resistance during normal breathing [3]. Therefore, the interpretation of data on pharyngeal volume alone is likely to provide imprecise information on this aspect of the study.

This comment refers to the article available at doi:10.1007/s00405-016-4015-4.

An author's reply to this comment is available at doi:10.1007/s00405-016-4119-x.

Om Prakash Kharbanda

opk15@hotmail.com

1 Division of Orthodontics and Dentofacial Deformities, Centre for Dental Education and Research, All India Institute of Medical Sciences, New Delhi 110029, India
The authors of current article have used data pertaining to pharyngeal airway volume alone, and therefore, the title and content are not complimentary. The authors may have some explanation for their study title and may like to throw more light on data outcome, which is limited to pharyngeal volume.

\section{Compliance with ethical standards}

Conflict of interest The authors declare that they have no conflict of interest to declare.

\section{References}

1. Rosário HD, Oliveira GM, Freires IA, Matos FS, Paranhos LR (2016) Efficiency of bimaxillary advancement surgery in increasing the volume of the upper airways: a systematic review of observational studies and meta-analysis. Eur Arch Otorhinolaryngol. doi:10.1007/s00405-016-4015-4

2. Morris IR (1988) Functional anatomy of the upper airway. Emerg Med Clin North Am 6:639-669

3. Ferris BG Jr, Mead J, Opie LH (1964) Partitioning of respiratory flow resistance in man. J Appl Physiol 19:653-658 